J. Dairy Sci. 98:719-719

http://dx.doi.org/10.3168/jds.2015-98-1-0719

(C) American Dairy Science Association ${ }^{\circledR}, 2015$.

\title{
Corrigendum to "Effects of alfalfa and cereal straw as a forage source on nutrient digestibility and lactation performance in lactating dairy cows" (J. Dairy Sci. 97:7706-7715)
}

\author{
B. Wang, S. Y. Mao, H. J. Yang, Y. M. Wu, J. K. Wang, S. L. Li, Z. M. Shen, and J. X. Liu
}

On page 7708 , the sample storage temperature should be $4^{\circ} \mathrm{C}$ (not $\left.-4^{\circ} \mathrm{C}\right)$. On page 7713 , the second complete sentence should read "Compared with CS or RS, AH had higher portions of soluble carbohydrates (soluble sugars and organic acids, and starch and pectin; Table 3 ), which may have increased the supply of the rumen fermentable energy for MCP synthesis.
The authors regret the errors.

\section{REFERENCE}

Wang, B., S. Y. Mao, H. J. Yang, Y. M. Wu, J. K. Wang, S. L. Li, Z. M. Shen, and J. X. Liu. 2014. Effects of alfalfa and cereal straw as a forage source on nutrient digestibility and lactation performance in lactating dairy cows. J. Dairy Sci. 97(12):7706-7715. 